\title{
Caminhos da cidadania cultural: o ensino de artes no Brasil
}

\section{Paths to cultural citizenship: learning arts in Brazil}

\author{
Marcelo Gruman ${ }^{1}$
}

\begin{abstract}
RESUMO
$\mathrm{O}$ artigo trata do ensino da arte nas escolas brasileiras a partir dos conceitos de multiculturalismo, diversidade cultural e cidadania cultural, norteadores da atuação do Ministério da Cultura a partir da gestão do ex-Ministro Gilberto Gil iniciada no ano de 2003. Argumenta que é imprescindível um diálogo cada vez mais intenso entre o Ministério da Cultura e o Ministério da Educação na consecução deste objetivo, qual seja, garantir o cumprimento do direito humano à educação e à participação na cultura, inscritos na Constituição Brasileira de 1988, e ratificado pela Convenção sobre a Promoção e Proteção da Diversidade das Expressões Culturais da UNESCO, ratificada pelo Brasil no ano de 2006.
\end{abstract}

Palavras-chave: arte; educação; diversidade cultural; UNESCO.

\begin{abstract}
The article deals with the learning of the arts in the Brazilian education system taking into account the concepts of multiculturalism, cultural diversity and cultural citizenship, guidelines of the public policies of the Ministry of Culture since 2003. It also argues the importance of the dialogue between the Ministries of Culture and Education to accomplish a common goal, that is, guarantee the human rights for education and culture, inscribed in the Brazilian Constitution of 1988 and ratified by the Brazilian Government in 2006 in the scope of the UNESCO's Convention for the Protection and Promotion of the Diversity of Cultural Expressions.
\end{abstract}

Keywords: art; education; cultural diversity; UNESCO.

1 Antropólogo, PhD. Fundação Nacional das Artes/ Ministério da Cultura (FUNARTE/ MinC), Brasil. E-mail: marcelogruman@gmail.com 


\section{Sobre os conceitos de cultura e arte: convergências}

Podemos dizer que "cultura" refere-se ao significado que um grupo social dá à sua experiência, incluindo aqui ideias, crenças, costumes, artes, linguagem, moral, direito, culinária etc. A cultura é dinâmica, se recicla incessantemente incorporando novos elementos, abandonando antigos, mesclando os dois transformando-os num terceiro com novo sentido. Tratamos, portanto, do mundo das representações, incorporadas simbolicamente na complexidade das manifestações culturais. Cultura não é acessório da condição humana, é sim seu substrato. $\mathrm{O}$ ser humano é humano porque produz cultura, dando sentido à experiência objetiva, sensorial. Afinal de contas, um macaco não é capaz de apreciar a diferença entre água benta e água destilada...

Tomo como referência os trabalhos de Sahlins (1979), para quem a razão simbólica ou significativa toma como qualidade distintiva do homem não o fato dele viver num mundo material, circunstância que compartilha com todos os organismos, mas o fato dele viver num mundo significativo criado por si próprio, qualidade que torna a humanidade única. Também compartilho do conceito de "cultura" defendido por Geertz (1989), segundo o qual o homem é um animal amarrado a teias de significados que ele mesmo teceu, sendo a cultura essas teias e sua análise. Este autor reconhece que não é possível apreendermos o significado tal qual ele é concebido pelos atores sociais, no entanto, acredita na possibilidade de interpretá-lo. A Antropologia, assim, é tida como uma ciência interpretativa, cuja força metodológica consiste no afastamento tanto do subjetivismo quanto do objetivismo.

Minha própria posição tem sido tentar resistir ao subjetivismo, de um lado, e ao cabalismo de outro, tentar manter a análise das formas simbólicas tão estreitamente ligadas quanto possível aos acontecimentos sociais e ocasiões concretas, o mundo público da vida comum, e organizá-la de tal forma que as conexões entre as formulações teóricas e as interpretações descritivas não sejam obscurecidas por apelos às ciências negras (mágicas). Nunca me impressionei com o argumento de que, como é impossível uma objetividade completa nesses assuntos (o que de fato ocorre), é melhor permitir que os sentimentos levem a melhor. Conforme observou Robert Solow, isso é o mesmo que dizer que, como é impossível um ambiente perfeitamente asséptico, é válido fazer uma cirurgia num esgoto. (GEERTZ, 1989, p. 40) 
A cultura é pública porque o significado também o é. É fundamental atentarmos para o fluxo do comportamento, da ação social, através do qual as formas culturais encontram articulação. O significado aflora do papel que desempenha no padrão de vida decorrente. Fica marcado, portanto, o caráter eminentemente social das identidades. Ainda aqui, os membros escolhem aderir ao conjunto de práticas e crenças vinculadas a tal identidade, "a mais essencial de todas as criações ou invenções modernas", nas palavras do sociólogo polonês Zygmunt Bauman.

Tomando como ponto de partida a ideia de Vigotsky (1991) sobre a importância do "outro" no processo de desenvolvimento do indivíduo, utilizo as interpretações de Anselm Strauss que, em seu clássico Espelhos e Máscaras (1999) afirma que nossas identidades são formadas a partir de avaliações feitas por nós mesmos e dos espelhos e julgamentos feitos pelos "outros". Acionamos códigos particulares, terminologias simbólicas específicas para dar conta de cada situação apresentada. A cada uma delas, atualizamos valores e comportamentos que nos dão a sensação de pertencimento ao grupo que nos avalia. Experimentar situações distintas apresentando em cada uma delas determinada máscara social faz parte deste mundo de escolhas característico da Modernidade. Somos confrontados com uma "pluralização dos mundos da vida" ou "setores do estilo de vida" (Giddens, 2002), para os quais necessitamos de ferramentas simbólicas particulares de modo a sermos reconhecidos como membros daquele ambiente de ação específico. Daí a importância da interação social do "outro", na construção dos espaços simbólicos onde expressamos nossa existência humana em termos de múltiplas identidades.

Portanto, quando se diz que alguém "não tem cultura", a referência é à sofisticação, sabedoria, de educação no sentido restrito do termo. Ou seja, pressupõe-se que o volume de leituras, controle de informações e títulos universitários equivalham à “inteligência”. A cultura em seu sentido antropológico, por outro lado, transcende a noção de refinamento intelectual (cujo adjetivo é "culto", e não "cultural"). A cultura permite traduzir melhor a diferença entre nós e os outros e, assim fazendo, resgatar a nossa humanidade no outro e a do outro em nós mesmos. (DA MATTA, 1981). Ao seguirmos essa perspectiva, tornamo-nos mais respeitosos com relação ao outro porque este outro nada mais é do que nosso espelho, refletindo a unidade na diversidade. Para além da tolerância, perseguimos a convivência e a harmonia.

Dar sentido à experiência, ao estar-no-mundo, representá-la através de símbolos e orientar os indivíduos uns em relação aos outros os dotando de máscaras sociais, de identidades, também é característica daquilo que entendemos por arte. Ela é cognição através dos sentidos. É uma área de conhecimento que opera com a organização imaginativa do sujeito a partir da experiência univer- 
sal da humanidade e das experiências particulares de cada um, resguardados os princípios da unidade na diversidade, da harmonia na heterogeneidade e do equilíbrio nas diferenças (PEREIRA, 1993), consolidando-se como fator de humanização, de socialização e de fortalecimento da identidade cultural.

A arte é um meio de representação da realidade, uma construção social, percepção de nós mesmos no mundo possibilitando-nos assumir modelos de identidade e comportamento. Tais representações do mundo podem nos inspirar para a compreensão do presente e criação de alternativas para o futuro. Nos Parâmetros Curriculares Nacionais de 1997, a arte é definida a partir de expressões como "conquista da significação", "experiência de apropriação", "desenvolvimento da percepção estética", "consciência do lugar no mundo", evidenciando o papel ativo do indivíduo no processo de construção de sua(s) identidade(s), posição distinta daquela advogada pelo ensino de arte tradicional que sacralizava a figura do professor, dono do saber.

Situa-se a área de Arte dentro dos Parâmetros Curriculares Nacionais como um tipo de conhecimento que envolve tanto a experiência de apropriação de produtos artísticos (que incluem as obras originais e as produções relativas à arte, tais como textos, reproduções, vídeos, gravações, entre outros) quanto o desenvolvimento da competência de configurar significações por meio da realização de formas artísticas. Ou seja, entende-se que aprender arte envolve não apenas uma atividade de produção artística pelos alunos, mas também a conquista da significação do que fazem, pelo desenvolvimento da percepção estética, alimentada pelo contato com o fenômeno artístico visto com objeto de cultura através da história e como conjunto organizado de relações formais. É importante que os alunos compreendam o sentido do fazer artístico; que suas experiências de desenhar, cantar, dançar ou dramatizar não são atividades que visam distraí-los da "seriedade" das outras disciplinas. Ao fazer e conhecer arte o aluno percorre trajetos de aprendizagem que propiciam conhecimentos específicos sobre sua relação com o mundo. Além disso, desenvolvem potencialidades (como percepção, observação, imaginação e sensibilidade) que podem alicerçar a consciência do seu lugar no mundo e também contribuem inegavelmente para sua apreensão significativa dos conteúdos das outras disciplinas do currículo (Parâmetros Curriculares Nacionais, 1997, p. 32). 


\section{O ensino de artes no Brasil e a UNESCO: respeito à diversidade cultural}

No dia 16 de novembro de 1945, em Londres, foi adotada a Constituição da recém-criada Organização das Nações Unidas para a Educação, Ciência e Cultura-UNESCO. Em seu preâmbulo, fica clara a influência dos acontecimentos recentes da Segunda Guerra Mundial, quando se afirma que "a ignorância dos modos de vida uns dos outros tem sido uma causa comum, através da história da humanidade, de suspeita e desconfiança entre os povos do mundo, causando guerras" e que "a difusão da cultura, a educação da humanidade para a justiça, a liberdade e a paz são indispensáveis para a dignidade do homem e constitui um dever sagrado que todas as nações devem preencher segundo o espírito de mútua assistência" (UNESCO, 1945, p. 1). O propósito da organização era, e é, o alcance, através de relações educacionais, científicas e culturais entre os povos do mundo, da paz internacional e da compreensão mútua. Pretendia-se, portanto, acabar com a arrogância etnocêntrica.

Mais de três décadas se passaram quando, em 1978, na Conferência de Bogotá, o plano elaborado para o período 1977-1982 deixava clara a importância do estudo de culturas regionais, muitas vezes fruto de combinações e ressignificações simbólicas entre o "dentro" e o "fora", trazendo também a questão da diversidade cultural intrassocial subestimada ou negligenciada no período pós-guerra mundial. Novamente vislumbramos a promoção da compreensão mútua como fonte de paz duradoura entre as nações:

a afirmação da identidade cultural por cada povo, seja ele politicamente soberano ou não, seja uma grande potência ou não, que disponha plenamente de recursos e técnicas ou que esteja ainda em desenvolvimento, é o fundamento do pluralismo cultural. O reconhecimento e o respeito por tal pluralismo, à igualdade de direitos e à dignidade, aparecem hoje como um fator de paz e de compreensão entre as nações (UNESCO, 1977, p. 11)

A ideia de que o pluralismo cultural poderia ser a "essência mesma da identidade cultural" questionava a imagem tradicional de Estados culturalmente monolíticos e introduzia a noção de "cultura da mestiçagem", chegando-se à conclusão de que "a diversidade cultural dos povos deve ser considerada como fator de equilíbrio e não de divisão".

Em 1982, ocorreu a Conferência MONDIACULT, na cidade do México, 
marcando significativamente a trajetória da UNESCO em suas atividades levadas a cabo no âmbito da cultura ao longo da década de oitenta. A Declaração do México sobre Políticas Culturais continha uma definição de cultura e uma explicação de seu papel:

Em seu sentido mais amplo, a cultura pode, hoje, ser considerada como o conjunto de traços distintivos, espirituais e materiais, intelectuais e afetivos que caracterizam uma sociedade ou grupo social. Ela engloba, além das artes e das letras, os modos de vida, os direitos fundamentais do ser humano, os sistemas de valores, as tradições e as crenças. (UNESCO, 1982, p. 39)

Quase duas décadas se passaram quando, em 2001, foi elaborada a Declaração Universal sobre a Diversidade Cultural. Nela, logo em seu artigo $1^{\circ}$ intitulado "diversidade cultural: herança comum da humanidade" é reforçada a ideia de que a cultura toma diversas formas ao longo do tempo e do espaço e que a diversidade está incorporada na unicidade e pluralidade das identidades grupais e societárias que representam a riqueza simbólica da humanidade. Como fonte de troca, inovação e criatividade, a diversidade cultural é "tão necessária para a espécie humana quanto a biodiversidade é para a natureza".

Talvez possamos considerar o artigo $2^{\circ}$ da Declaração Universal sobre Diversidade Cultural como o "pulo do gato" para o estabelecimento de relações harmoniosas entre as nações e no interior delas, uma vez que, como visto acima, o paradigma do Estado-Nação culturalmente monolítico já havia sido questionado tanto pela UNESCO quanto por instituições acadêmicas. O ideal a ser alcançado é, portanto, o pluralismo cultural, que não deve ser confundido simplesmente com a diversidade de manifestações culturais, mas como conhecimento e respeito ao "outro". É, na linguagem antropológica, estranhar o familiar e aproximar-se do estranho, tornando-o familiar:

Mesmo que um dia tenha sido possível e mesmo que hoje provoque saudades, a soberania do familiar empobrece a todos; enquanto ela tiver um futuro, na mesma medida, o nosso é tenebroso. Não é que tenhamos que amar um ao outro (se for assim - negros e afrikaners, árabes e judeus, tâmiles e cingaleses - acho que estamos condenados). Temos é de conhecer um ao outro, e viver com este conhecimento, ou acabar como náufragos num mundo beckettiano de solilóquios em colisão (GEERTZ, 1999, p. 30). 
Eis a transcrição do texto do artigo $2^{\circ}$ da Declaração Universal sobre Diversidade Cultural:

In our increasingly diverse societies, it is essential do ensure harmonious interaction among people and groups with plural, varied and dynamic cultural identities as well as their willingness to live together. Policies for inclusion and participation of all citizens are guarantees of social cohesion, the vitality of civil society and peace. This defined, cultural pluralism gives policy expression to the reality of cultural diversity. Indissociable from a democratic framework, cultural pluralism is conducive to cultural exchange and to the flourishing of creative capacities that sustain public life. (UNESCO, 2002, p. 2)

O último documento produzido pela UNESCO no que se refere à questão da diversidade cultural foi a Convenção sobre a Proteção e Promoção da Diversidade das Expressões Culturais, celebrado em Paris durante a $33^{\mathrm{a}}$ reunião da Conferência Geral da Organização das Nações Unidas entre os dias 3 e 21 de outubro de 2005. O texto oficial foi ratificado pelo Brasil por meio do Decreto Legislativo 485/2006. No preâmbulo dos artigos, o texto recorda ao público leitor que a cultura e a diversidade cultural são, dentre outras coisas, uma característica essencial da humanidade; constituem seu patrimônio comum, a serem valorizados e cultivados em benefício de todos; ao florescerem em ambiente democrático, de tolerância, justiça social e mútuo respeito entre povos e culturas, são indispensáveis para a paz e a segurança nos planos local, regional e internacional; elementos estratégicos das políticas de desenvolvimento nacionais e internacionais; manifestam-se na originalidade e pluralidade de identidades; fontes de coesão social; se fortalecem mediante a livre circulação de ideias e se nutrem das trocas constantes e da interação entre os grupos sociais.

Uma série de princípios chama a atenção para o fato de que nenhuma medida ou política destinada à proteção e promoção da diversidade de expressões culturais pode infringir os direitos humanos e as liberdades fundamentais como a de expressão, informação e comunicação, bem como a liberdade dos indivíduos se expressarem culturalmente. Os países que ratificaram a Convenção estão obrigados a promover em seus territórios a criação de um ambiente que encoraje os indivíduos e os grupos sociais a criarem, produzirem, disseminarem, distribuírem e acessarem suas expressões culturais, bem como acessarem as demais expressões culturais dentro de seu território e de outros países do mundo.

Estudiosos de arte-educação afirmam que um dos poucos avanços edu- 
cacionais no Brasil nos últimos anos foi a introdução da preocupação com multiculturalidade nas escolas, entendida como o reconhecimento de diferentes códigos culturais e de diferentes necessidades culturais, da necessidade de convivência entre culturas e dentro da mesma cultura (BARBOSA, 2002; AGUIRRE; JIMÉNEZ, 2009). Na escola tradicional, baseada na pedagogia neoclássica, valorizavam-se principalmente as habilidades manuais, os "dons artísticos", os hábitos de organização e precisão, mostrando ao mesmo tempo uma visão utilitarista da arte.

\begin{abstract}
Afastando-se a arte do contato popular, reservando-a para the happy few e os talentosos, concorria-se, assim, para alimentar um dos preconceitos contra a arte hoje acentuada em nossa sociedade, a idéia de arte como uma atividade supérflua, um babado, um acessório da cultura (BARBOSA, 1978, p. 20)
\end{abstract}

Seu ensino era voltado essencialmente para o domínio técnico, mais centrado na figura do professor. As atividades de teatro e dança eram reconhecidas quando faziam parte das festividades escolares na celebração de datas como o Natal, Páscoa ou Independência, ou nas festas de final de período escolar. O teatro era tratado com uma única finalidade: a da apresentação. As crianças decoravam os textos e os movimentos cênicos eram marcados com rigor.

As Orientações Curriculares para o Ensino Médio - Linguagens, Códigos e suas Tecnologias, publicado em 2006 pelo Ministério da Educação, é um exemplo de como o tema da diversidade cultural entrou na agenda do Estado brasileiro quando o assunto é ensino das artes. O item 1.6, intitulado "diversidade e pluralidade cultural", afirma que o ideário sobre o Ensino da Arte contempla as "diferenças de raça, etnia, religião, classe social, gênero, opções sexuais e um olhar mais sistemático sobre outras culturas", denunciando, ainda, a ausência das mulheres na história da arte e nos seus circuitos de difusão, circulação e prestígio. Considera a educação especial, tomando o aluno de necessidades educacionais especiais como detentor de uma cultura de minoria no espaço escolar, pondo em pauta a necessidade de reforçar a herança estética e artística dos alunos de acordo com seu meio ambiente, e exige valores estéticos mais democráticos, chamado de alfabetização cultural: possibilitar que aluno desenvolva competências em múltiplos sistemas de percepção, avaliação e prática da arte.

Sugere o mesmo documento, em suas proposições referentes à "inclusão, diversidade e multiculturalidade", que, embora a diferença exerça um papel decisivo nas relações interculturais, quando se "respeita" ou se "aceita" de ma- 
neira passiva, corre-se o risco de se ter uma mera atitude de "tolerância", pois já há a suposição de que há um lugar superior a ser ocupado. Como no ensino da Arte ainda vigoraria o padrão eurocêntrico, seria necessário questionar os jogos de poder que legitimam as diferenças como verdades artísticas, estéticas e culturais. O raciocínio presente aqui é semelhante ao apresentado nos documentos da UNESCO, quando se advoga a mudança de percepção da sociedade contemporânea, não tanto diversa quanto plural, cujos fluxos simbólicos são constantes e não respeitam supostas fronteiras de identidade intransponíveis. Se aceita, portanto, que a arte ocidental ou "eurocêntrica" não é, senão, uma das manifestações da "inquietude estética do gênero humano" (AGUIRRE; JIMÉNEZ, 2009).

A diversidade não implica em aceitação incondicional dos modos de vida do "outro", mas na compreensão que o "outro" tem suas razões para se comportar de tal ou qual maneira, de acreditar nisto ou naquilo, ainda que eu não considere a melhor maneira de se comportar ou de pensar. Ademais, o contato estimula a criatividade. Como bem disse o antropólogo Lévi-Strauss:

As grandes épocas criadoras foram aquelas em que a comunicação se tornara suficiente para que parceiros afastados se estimulassem, sem que, no entanto, fosse excessivamente freqüente e rápida para que obstáculos, tão indispensáveis entre os indivíduos como entre os grupos, se reduzissem, a ponto de trocas demasiado fáceis virem igualar e confundir a sua diversidade (LÉVI-STRAUSS, 1986, p. 48).

A Declaração Universal sobre a Diversidade Cultural almeja a preservação da diversidade cultural como um tesouro vivo e renovável que deve ser percebido como um processo garantidor da sobrevivência humana. Almeja, por consequência, a prevenção da segregação e do fundamentalismo que, em nome de diferenças culturais, as santifica. A "fé fundamentalista na diferença naturalizada" (CAVALCANTI-SCHIEL, 2007) se coaduna com o discurso daqueles que dizem que as minorias constituem grupos autenticamente diferentes do ponto de vista de seus próprios membros, são o que são porque cada grupo tem sua própria cultura.

A educação multicultural de corte reformista se limita a introduzir mudanças nas velhas configurações curriculares para favorecer o encontro cultural. Recebeu inúmeras críticas, porque simplesmente acomodaria as diferenças. Fazer da "tolerância" o foco dos programas educativos não só não rompe o jogo de hegemonias, como mascara a manutenção dos privilégios de "raça" e classe. 
A "tolerância" mesma encerra um sentido de aceitação cortês do rechaçado (AGUIRRE; JIMÉNEZ, 2009). Por outro lado, o corte reconstrucionista inclui entre seus principais propósitos o de reparar séculos de desigualdade social e cultural, para o qual não é suficiente retocar o currículo, mas proceder à total transformação de seus pressupostos educativos e recuperar as memórias estéticas anteriormente negadas.

Entramos na seara da "cidadania cultural", expressão que diz respeito à superação das desigualdades, ao reconhecimento das diferenças reais existentes entre os sujeitos em suas dimensões social e cultural, pressupõe a participação em múltiplos contextos simbólicos, em múltiplos pertencimentos, em múltiplas identidades, em inúmeras "províncias de significado" (SCHUTZ, 1973). A ideia de cidadania cultural se insere numa perspectiva democrática e toma os indivíduos não como consumidores e contribuintes, mas os considera como sujeitos políticos. A cultura é vista como direito dos cidadãos, e nessa medida eles têm o direito à informação, ao debate e à reflexão; o direito de produzir cultura; o direito de usufruir os bens da cultura; o direito à invenção de novos significados culturais; o direito à formação cultural e artística; o direito à experimentação e ao trabalho cultural crítico e transformador. Reconhece-se que a cidadania também se constrói a partir do respeito às formas como os indivíduos se veem e, mais ainda, querem ser vistos pelos outros.

O conceito de diversidade cultural nos permite perceber que as identidades culturais brasileiras não são um conjunto monolítico e único. Ao contrário, podemos e devemos reconhecer e valorizar as nossas diferenças culturais, como fator para a coexistência harmoniosa das várias formas possíveis de brasilidade. Como o respeito a eventuais diferenças entre os indivíduos e grupos humanos é condição da cidadania, devemos tratar com carinho e eficácia da promoção da convivência harmoniosa, dos diálogos e dos intercâmbios entre os brasileiros - expressos através das diversas linguagens e expressões culturais, para a superação da violência e da intolerância entre indivíduos e grupos sociais em nosso país. (MAMBERTI, 2003, p. 14)

O multiculturalismo tupiniquim quer "tudo junto e misturado", sem apagar as fronteiras culturais. As trocas de experiências fortalecem as fronteiras, mais do que as apagam, uma vez que o significado que "entra" é ressemantizado de acordo com a visão de mundo de quem está "dentro". Incorpora-se, ou tenta-se incorporar, a dimensão antropológica do conceito de cultura que tem em vista 
a formação global do indivíduo, a valorização de seus modos de viver, pensar e fruir, de suas manifestações simbólicas e materiais, e que busca, ao mesmo tempo, ampliar seu repertório de informação cultural, enriquecendo e alargando sua capacidade de agir sobre o mundo. Talvez, segundo Hermano Vianna (1999), possamos pensar no indivíduo moderno como o terno personagem de Fernando Pessoa, partindo do princípio de que somos todos transeuntes de tudo, somos "poliédricos" (AGUIRRE; JIMÉNEZ, 2009), de que nada nos diz nada e criando um espaço de compreensão do modo de vida e da visão de mundo dos "outros".

Somos humanos porque somos seres produtores e produtos de cultura, porque construímos socialmente nossa realidade, porque arbitrariamente damos sentido à nossa existência. Esta existência e seus valores são representados simbolicamente de diversas maneiras, uma delas sendo a atividade artística. Enquanto conhecimento, devem ser praticadas e ensinadas nas escolas, ser parte integrante dos currículos. É esta a recomendação que encontramos nas Conclusões do Congresso Ibero-americano de Educação Artística: sentidos transibéricos, ocorrida na cidade portuguesa de Beja, em 2008:

As artes são essenciais para o conhecimento. Como são praticadas por todas as sociedades e são elementos determinantes da cultura e do desenvolvimento psicossocial do indivíduo, devem ser parte integrante de todos os currículos educativos, não como um elemento marginal ou externo ao sistema educativo. Assim, a Educação Artística (incluindo as artes plásticas, música, teatro, dança etc.) deve estar integrada como uma das áreas curriculares essenciais da Educação. Como estratégia de reação ante um crescente tecnocentrismo dos currículos educativos é necessário retomar o valor das emoções, posto que são elas que nos orientam em direção ao demais e porque verdadeiramente nos conferem a humanidade. Como reação à negação da Escola em relação ao papel dos sentimentos na formação dos futuros cidadãos é preciso que o afetivo, $o$ emotivo, o biográfico, o subjetivo, adquiram de novo um lugar essencial na cotidianidade das aulas (CONGRESSO IBERO-AMERICANO DE EDUCAÇÃO ARTÍSTICA, 2008)

No Roteiro para a Educação Artística, documento elaborado por ocasião da Conferência Mundial sobre Educação Artística (Lisboa, 2006) foi explicitado que cultura e arte, como direito universal, são componentes básicos de uma Educação Integral que permita o desenvolvimento pleno do indivíduo. Este é, portanto, um desafio posto ao Estado brasileiro, garantir o cumprimento do direito humano à educação e a participação na cultura. Cabe às instituições go- 
vernamentais responsáveis pela gestão de programas diretamente relacionados ao objetivo mencionado zelar por seu cumprimento, os Ministérios da Educação e Cultura que, após mais de vinte anos de "divórcio", reataram laços que nunca deveriam ter sido rompidos.

\section{REFERÊNCIAS}

ABAD, J. Usos y funciones de las artes en la educación y el desarrollo humano. In: JIMÉNEZ, Lucina; AGUIRRE, Imanol; PIMENTEL, Lucia G. (coords). Educación artística, cultura y cidadania. Madrid: Fundación Santillana/OEI, 2009.

AGUIRRE, I.; JIMÉNEZ, L. Diversidad cultural y educación artística. In: JIMÉNEZ, Lucina; AGUIRRE, Imanol; PIMENTEL, Lucia G. (Coords). Educación artística, cultura y cidadania. Madrid: Fundación Santillana/OEI, 2009.

BARBOSA, A. M. Arte e Inclusão. Caderno de Textos: educação, arte, inclusão, Rio de Janeiro, v.1, n. 1, 2002. . Arte-educação: conflitos/acertos. São Paulo: Max Limonad. 1985. . Arte-educação no Brasil. São Paulo: Perspectiva: 1978.

CAVALCANTI-SCHIEL, R. Quando nem todos os cidadãos são pardos. In: FRY, P.; MAGGIE, Y.; CHOR MAIO, M.; MONTEIRO, S.; SANTOS, R. V. (Orgs.). Divisões perigosas: políticas raciais no Brasil contemporâneo. Rio de Janeiro: Civilização Brasileira. 2007.

CONGRESSO IBEROAMERICANO DE EDUCAÇÃO ARTÍSTICA: SENTIDOS TRANSIBÉRICOS. 22 a 24 de maio de 2008. Beja, Portugal.

DA MATTA, R. Você tem cultura? Jornal da Embratel. Rio de Janeiro, 1981.

GEERTZ, C. A interpretação das culturas. São Paulo: LTC, 1989.

GIDDENS, A. Modernidade e Identidade. Rio de Janeiro: Jorge Zahar Editor, 2002.

HENRIQUES, R. Arte e Educação: cerzir fronteiras, enunciar territórios. In: RIBEIRO, J. M. B. (Org.). Trajetória e políticas para o ensino das artes no Brasil: anais da XV CONFAEB. Brasília: MEC, 2006.

LÉVI-STRAUSS, C. O olhar distanciado. Lisboa: Ediçoes 70, 1986.

MAMBERTI, S. Por uma cultura democrática. In: BRANT, L. (Org.). Políticas culturais v.1 São Paulo: Manole, 2003.

MINISTÉRIO DA EDUCAÇÃO. Orientações curriculares para o ensino médio - linguagens, códigos e suas tecnologias. Brasília, 2006. 
. Parâmetros curriculares nacionais. Brasília, 1997.

PEREIRA, M. V. Ofício da FAEB ao Ministro da Educação e Desporto. Brasília, 1993.

SAHLINS, M. Cultura e razão prática. Rio de Janeiro: Zahar Editores, 1979.

SCHUTZ, A. On phenomenology and social relations. Chicago: The University of Chicago Press, 1973.

STRAUSS, A. Espelhos e máscaras. São Paulo: EDUSP, 1999.

TACUCHIAN, R. A música na educação como processo. In: PEREIRA, M. L. M. (Coord.). Arte como processo na educação. Rio de Janeiro: FUNARTE, 1982.

UNESCO. Hoja de Ruta para la Educación Artística. In: CONFERÊNCIA MUNDIAL SOBRE LA EDUCACIÓN ARTÍSTICA: CONSTRUIR CAPACIDADES CREATIVAS PARA EL SIGLO XXI, 2006, Lisboa, Portugal.

. Convenção sobre a proteção e a promoção da diversidade das expressões culturais. Brasília: UNESCO, 2006.

. Declaração Universal sobre a Diversidade Cultural. Paris: UNESCO, 2002.

. Planejamento de médio prazo, 1977-1982. Paris: UNESCO, 1997.

. Mexico City Declaration on Cultural Policies. Paris: UNESCO, 1982.

. Constitution of the United Nations Educational, Scientific and Cultural Organization, Londres: UNESCO, 1945.

VIANNA, H. Ternura e atitude blasé na Lisboa de Pessoa e na Metrópole de Simmel. In: VELHO, G. (Org). Antropologia urbana: cultura e sociedade no Brasil e em Portugal. Rio de Janeiro: Jorge Zahar, 1999.

VYGOTSKY, L. S. A formação social da mente. São Paulo: Martins Fontes, 1991.

Texto recebido em 07 de maio de 2010.

Texto aprovado em 05 de julho de 2010. 
